\title{
The effect of different Newcastle disease live vaccines and vaccination schedules on the immune response and performance of broiler chickens serologically positive to Mycoplasmas
}

\author{
M. M. Amer*, Wafaa. A. Abd El-Ghany \\ Department of Poultry Diseases, Faculty of Veterinary Medicine, Cairo University, Egypt.
}

This study was conducted to investigate the efficacy of the Newcastle disease (ND) live vaccines from different commercial sources used in different programs for vaccination of chicks having maternal antibodies against Mycoplasma infection. The immune response was estimated using HI and challenge tests. The effect on the chicken performance was estimated by the detection of the body weight gain. The role of vaccines in stimulating respiratory bacterial stress was pointed out by the lesion scores.

Birds vaccinated with live vaccines from source (2) showed higher HI titers than those vaccinated with vaccine from source (1) and birds received the $2^{\text {nd }}$ vaccination from heterologous source showed lower titers than those received from homologous source.

Results of the challenge test indicated that birds vaccinated with live ND vaccines from one source and those vaccinated with Hitchner B1 at 33-days of age instead of La Sota showed $100 \%$ protection rate as compared with $95 \%$ followed by vaccination with heterologous La Sota. Birds received Hitchner B1 of vaccine source (1) showed only $85 \%$ protection rate. All vaccinated chicken groups showed feed conversion rates lower than the non-vaccinated control one. Groups received Hitchner $B_{1}$ as a $3^{\text {rd }}$ dose of the vaccine showed higher rates than those vaccinated with La Sota.

Results of the lesion score for chronic respiratory disease (CRD) in vaccinated groups with different regimes revealed that birds received ND vaccinal strains from source (1) having higher scores than those received ND vaccines from the 2nd source. Administration of Hitchner B1 vaccine at 33-days of age showed lower scores. Hitchner B1 can be recommended in vaccination of chickens derived from Mycoplasma infected hens.

Until now vaccination of chickens against Newcastle disease (ND) still the only effective policy for prevention and control (Saif et al., 2003; OIE, 2004). Since the recognition of the disease in Egypt velogenic viscerotropic strain of the virus became endemic (Lancaster and Alexander, 1975), and still reported to cause severe outbreaks with high losses in infected flocks. Until now, there is no data about the antigenic variation among NDV isolates, circulating in the poultry reared in Egypt.

ND vaccine production subjected to a continuous development to face the requirements of poultry men and that depending on the flock conditions, the aim of production, the prevalence of the latent infections as well as the epidemio-

\footnotetext{
* Corresponding author. Tel.: +20 121770699;

fax: +2025716840 .

E-mail address: profdramer@yahoo.com (M. M. Amer).
}

logical status of the disease.

On the other hand, considerable variations exist among the same strains produced by different manufacturers (Borland and Allan, 1980; Thronton et al., 1980). The demonstrated immunity was also different (Bunens et al., 1983). Furthermore, the field ND viruses are found to be different antiginically from the used vaccines (Panshsin et al., 2002). Eidson and Kleven, (1980) stated that ND vaccinal strains had the same pathogenic index differ in their immunogenicity based on geometric mean titers and challenge.

Live vaccines are different in their characters, mimic natural infection and induce circulating antibodies, secreted antibodies producing mucosal immunity and cell-mediated immunity (Allan et al., 1975).

An effective vaccination program must minimize the risk associated with the disease and 
maximize production efficiency in an economic and practical manner. Hitchner B1 (Hitchner and Johnson, 1948) and La Sota (Goldhaft, 1980) strains are now the most widely used vaccines. Recent work indicated an antigenic variation among the NDV strains (Russell and Alexander, 1983).

Mycoplasmas may affect the cell-mediated immune system by inducing either suppression or stimulation of $\mathrm{B}$ and $\mathrm{T}$ lymphocytes and inducing cytokines (Chabra and Goel, 1981; Reddy et al., 1998; Gaunson et al., 2000). On the other hand, Amer et al., (1993) reported the immunosuppressive effect of Mycoplasma spp. in chickens vaccinated with Newcastle Hitchner $B 1$ vaccine. In addition, Mycoplasma infections, could be aggravated by other bacteria and viruses to induce respiratory affections adversely affect chickens performance (MacOwan et al., 1982; Gross, 1990; Nakamura et al., 1994).

This work planed to study the efficacy of using of live Newcastle disease vaccines from different commercial sources in different vaccination programs on the immune response, the protection and the performance of broiler chicks serologically positive to Mycoplasmas.

\section{Material and Methods}

Chicks. Four hundreds and fifteen day old Cobb chicks were obtained from commercial farm at hatching. These chicks were floor reared and fed on commercial balanced ration with amprole plus and tylan premix as feed additive. The ration was given to the experimental birds $a d$ libitum.

\section{Newcastle disease (ND) viruses.}

\section{A. Vaccinal viruses.}

1. Source (1). Nobles vaccines including Hitchner $B_{1}$ (NB) Lot No. 053176D and La Sota (NL) Lot No. 058166D produced by Intervet Co., Boxmeer, Holland. Titers of these vaccines were estimated to be $10^{9.28}$ and $10^{9.56}$ EID 50 /vial 1000 dose; respectively.

2. Source (2). Liopest vaccines including Liopest B1 (LB) Lot No. N2/939 and Liopest La Sota (LL) Lot No V/02 produced by Iven laboratory, Maderd, Spain. They contained $10^{9.15}$ and $10^{9.42} \mathrm{EID}_{50} /$ vial 1000 dose respecttively.

B. La Sota virus. Laboratory La Sota strain was obtained from Veterinary Serum and Research Institute, Abassia, Cairo, Egypt and passed in SPF chicken embryo to be used as antigen for HI test.

C. Challenge virus. The local velogenic viscerotropic ND strain that was isolated from field outbreak and identified by Sheble and Reda, (1976) was used for challenge test.

Infecious bursal disease vaccine. All chicks were vaccinated at the $12^{\text {th }}$ day of life with intermediate plus vaccine (E.228) (Intervet Co., Boxmeer, and Holland) against infectious bursal disease using eye drop route.

Fertile eggs. Fertile Specific Pathogen Free (SPF) eggs (Kom Oshem, Fayom, Egypt) were used for titration of the used vaccines, challenge virus, passage of $\mathrm{HI}$ antigen as well as virus reisolation from dead challenged birds.

Detection of virus infectivity. Both of and challenge ND strains were titrated in 9-day-old SPF emberyonated chicken eggs before their use according to Anon (1971). Embryo Infective Dose $_{50}\left(\mathrm{EID}_{50}\right)$ was calculated according to Reed and Muench (1938).

Haemagglutination inhibition (HI) test. The $\beta$ procedure of micromethodology according to Takatsy, (1956) was used. HI-titers were given titers reference numbers according to Kaleta and Sigmonn, (1971) and the antibody titers were calculated as arithmetic mean of $\log _{2}$ end points. Vaccination. All used ND vaccines were applied allover this work using the eye drop method by instillation of $0.05 \mathrm{ml}$ containing a dose of $10^{6}$ EID $_{50}$ bird.

Lesion score. Lesion score for chronic respiratory disease (CRD) were estimated at 40day-old sacrificed birds according to Awaad et al., (2003).

Challenge test. Experimental chickens were intra-nasally infected each with $0.2 \mathrm{ml}$ of saline containing $10^{6}$ EID ${ }_{50}$ of velogenic viscerotropic ND (VVND) virus. Symptoms, mortalities and post-mortem lesions were recorded during 10 days observation period post challenge. Samples for virus reisolation were taken from dead birds. All survived birds were sacrificed and subjected to post mortem examination for ND lesions.

Serum samples. Twenty-five clotted blood samples for sera were individually collected at 1 and 7 days of age for detection of maternal $\mathrm{HI}$ antibodies against ND as well as at 14, 19, 26, 33 and 40-days of age to detect HI antibody in vaccinated and control groups. The sera were individually separated, labeled, heat inactivated and kept freeze until HI testing.

Mycoplasma antigen and antiserum Mycoplasma gallisepticum (MG) and Mycoplasma synoviae (MS) colored antigens were purchased from Intervet Co. and used for serum plate agglutination test. Chicken anti- $M G$ and- $M S$ sera were kindly gifted from 

Mycoplasma Department, Animal Health Research Institute, Dokki, Giza, Egypt.

Statistical analysis. The obtained results were statistically analyzed using ANOVA test at $\mathrm{P}<$ $0.001,0.01$ and 0.05 .

Experimental design. The used chicks (415) were floor reared. At the first day of life, 25 chicks were weighed and sacrificed and their blood was collected for separation of sera. Those birds were subjected to bacteriological examination for detection of pathogenic bacterial infection.

At the $7^{\text {th }}$ day of life, the remaining chicks (390) were equally divided into 13 groups (113), 30 chicks each. Each group was kept separately. Chicken groups 1-6 and 7-12 were vaccinated against ND using $\mathrm{LB}$ and $\mathrm{NB}$ vaccine respectively. Chicks of group 13 kept as nonvaccinated control. All chicken groups were vaccinated against infectious bursal disease via eye drop at the $12^{\text {th }}$ day of age.

At the $19^{\text {th }}$ day, birds of groups $1-3,4-6,7-9$ and 10-12 were received NL, LL, NL and LL vaccines, respectively. Two weeks after (33-days of age), birds of groups 1, 5, 7 and 10;2, 4, 8, and $11 ; 3$ and 9; as well as 6 and 12 were revaccinated with $\mathrm{NB}, \mathrm{LB}, \mathrm{NL}$ as well as LL vaccines; respectively (Table 2 ).

The consumed feed was recorded and the body weight of $25 \mathrm{bird} /$ group was detected weekly for 6 weeks to calculate the feed conversion rate at the $40^{\text {th }}$ day of life.

From each group, 25 clotted blood samples were randomly collected for sera at 7, 14, 19, 26, 33 and 40-days of age to determine HI antibodies against ND using $\mathrm{HI}$ test.

At the $40^{\text {th }}$ day of age, 10 birds / group were sacrificed and subjected to post-mortem examination for estimation of CRD lesion score. The remaining birds in all chicken groups (20 chickens / group) were challenged (each bird was taken $0.2 \mathrm{ml}$ containing $10^{6} \mathrm{EID}_{50}$ VVND via intra-nasal route). The challenged birds were kept under daily observation for 10 days for clinical signs, mortalities, post-mortem lesions as well as virus reisolation from dead birds. The protection rate was calculated at the end of observation period.

\section{Results}

Bacteriological examination of experimental sacrificed birds showed negative results to bacterial pathogen. Testing of the collected sera at 1 and 7 days of age against stained Mycoplasma antigen using plate agglutination test proved the detection of $36 \%$ and $28 \%$ as well as $44 \%$ and $60 \%$ for $M G$ as well as $M S$, respectively (Table 1 ).

Statistical analysis of HI results (Table 2, 3 Fig. 1) showed that the obtained mean titers at 40-days of age in group $6(7.21 \pm 1.78)$, group 8 $(7.31 \pm 2.25)$ at $\mathrm{P}<0.001$ and group $11(6.88 \pm$ $1.01)$ at $\mathrm{P}<0.05$ were significantly higher than those of groups $1(5.20 \pm 1.66)$, group $3(5.20 \pm$ $1.20)$ and group $5(5.25 \pm 0.89)$. HI mean titers in groups 6 and 8 were significantly higher than that of group $2(5.57 \pm 1.20)$ at $\mathrm{P}<0.05$. Titers of group $8(7.31 \pm 2.25)$ was significantly higher than those of groups $9(5.77 \pm 1.87)$ and $10(5.73$ $\pm 1.61)$ at $\mathrm{P}<0.05$.

Generally, it was observed that chicken group received $\mathrm{LB}$ and LL vaccine showed higher $\mathrm{HI}$ mean titers than those received $\mathrm{NB}$ and NL vaccines (group 6 and 9). On the other hand, bird received LB and /or LL vaccines at any time of vaccination showed relatively higher titers. Statistically, the results of the mean body weight at the $6^{\text {th }}$ week of age $($ Table 4,5$)$ indicated that birds of non-vaccinated control group showed significantly higher mean body weight $(1311 \pm$ 102.32) than those of vaccinated groups 1 (1139 $\pm 129.2)$, group $2(1191 \pm 110.8)$, group 3 (1154 $\pm 82.1)$, group $6(1156 \pm 85.5)$ and group 10 $(1125 \pm 105.8)$ at $\mathrm{P}<0.001$.

Body weight in-group 10 was significantly lower than those of group 7 (1295 \pm 140$)$, group $8(1281 \pm 114.3)$ at $\mathrm{P}<0.001$ as well as lower than that of group $9(1238 \pm 77.9)$ at $\mathrm{P}<0.05$. In addition, the obtained mean body weight values in groups 4,7 and 8 were significantly higher than those of groups $1(\mathrm{P}<0.001)$ and $3(\mathrm{P}<0.01)$.

Generally, the results in Tables $(4,5)$ indicated that using of vaccines from the same source resulted in improved body weights than the using of vaccines from heterologous sources. LB and LL vaccines induced relatively higher values.

Feed conversion rates in Table (4) Fig. (3) showed that all vaccinated chicken groups showed lower rate than the control nonvaccinated one. Birds of groups 1 2, 3, 5, 7, 9, 10,11 and 12 had rates of $2.40,2.29,2.55,2.37$, $2.32,2.32,2.35,2.28$ and 2. 23 , respectively which were lower than those of groups 4,6 and $8(2.10,2.12$ and 2.16), respectively. Groups received La Sota ND strain vaccine at 33-days of age mostly showed lower rates than those received Hitchner $\mathrm{B}_{1}$. Groups received NB and NL vaccines strains had lower rates than those 
Table (1): Results of MG and MS plate agglutination test.

\begin{tabular}{cccccc}
\hline \multirow{2}{*}{ Age } & \multirow{2}{*}{ No. of samples } & \multicolumn{2}{c}{ MG } & \multicolumn{2}{c}{ MS } \\
\cline { 3 - 5 } & 25 & No. of positive & \% & No. of positive & \% \\
\hline \multirow{2}{*}{ 1 day } & 25 & 9 & 36 & 11 & 44 \\
days & 7 & 28 & 15 & 60 \\
\hline
\end{tabular}

$\mathbf{M G}=$ Mycoplasma gallisepticum

MS=Mycoplasma synoviae

Table (2): Results of HI mean antibody titers in sera of chickens vaccinated against ND using different vaccination models. $(n=25)$.

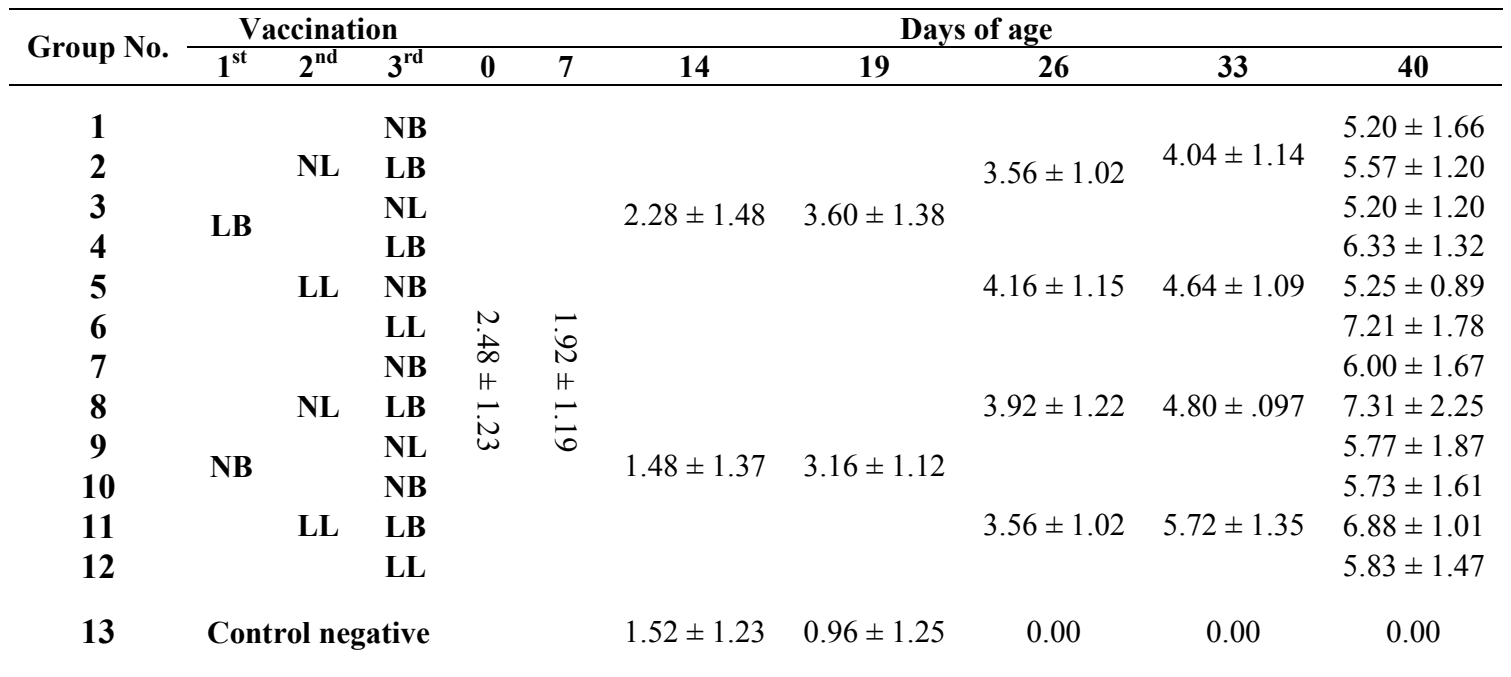

$\mathbf{N B}=$ Nobles Hitchner $\mathbf{B}_{1} . \quad \mathbf{N L}=$ Nobles La Sota. $\mathbf{L B}=$ Liopest $\mathbf{B}_{1} . \quad \mathbf{L}=\overline{\mathbf{L}}=$ Liopest La Sota.

Table (3): Results of statistical analysis of HI-titres between groups at 40-days of age as seen in table (2).

\begin{tabular}{|c|c|c|c|c|c|c|c|c|c|c|c|c|c|}
\hline Group No. & 1 & 2 & 3 & 4 & 5 & 6 & 7 & 8 & 9 & 10 & 11 & 12 & 13 \\
\hline 1 & & & & & & $* *$ & & $* * *$ & & & $*$ & & \\
\hline 2 & & & & & & $*$ & & $*$ & & & & & \\
\hline 3 & & & & & & $* *$ & & $* * *$ & & & $*$ & & \\
\hline 4 & & & & & & & & & & & & & \\
\hline 5 & & & & & & $* * *$ & & $* * *$ & & & $*$ & & \\
\hline 6 & & & & & & & & & & & & & \\
\hline 7 & & & & & & & & & & & & & \\
\hline 8 & & & & & & & & & $*$ & $*$ & $*$ & & \\
\hline 9 & & & & & & & & & & & & & \\
\hline 10 & & & & & & & & & & & & & \\
\hline 11 & & & & & & & & & & & & & \\
\hline 12 & & & & & & & & & & & & & \\
\hline 13 & & & & & & & & & & & & & \\
\hline
\end{tabular}


Table (4): Results of weekly mean body weight of ND vaccinated chicken groups $(n=25)$.

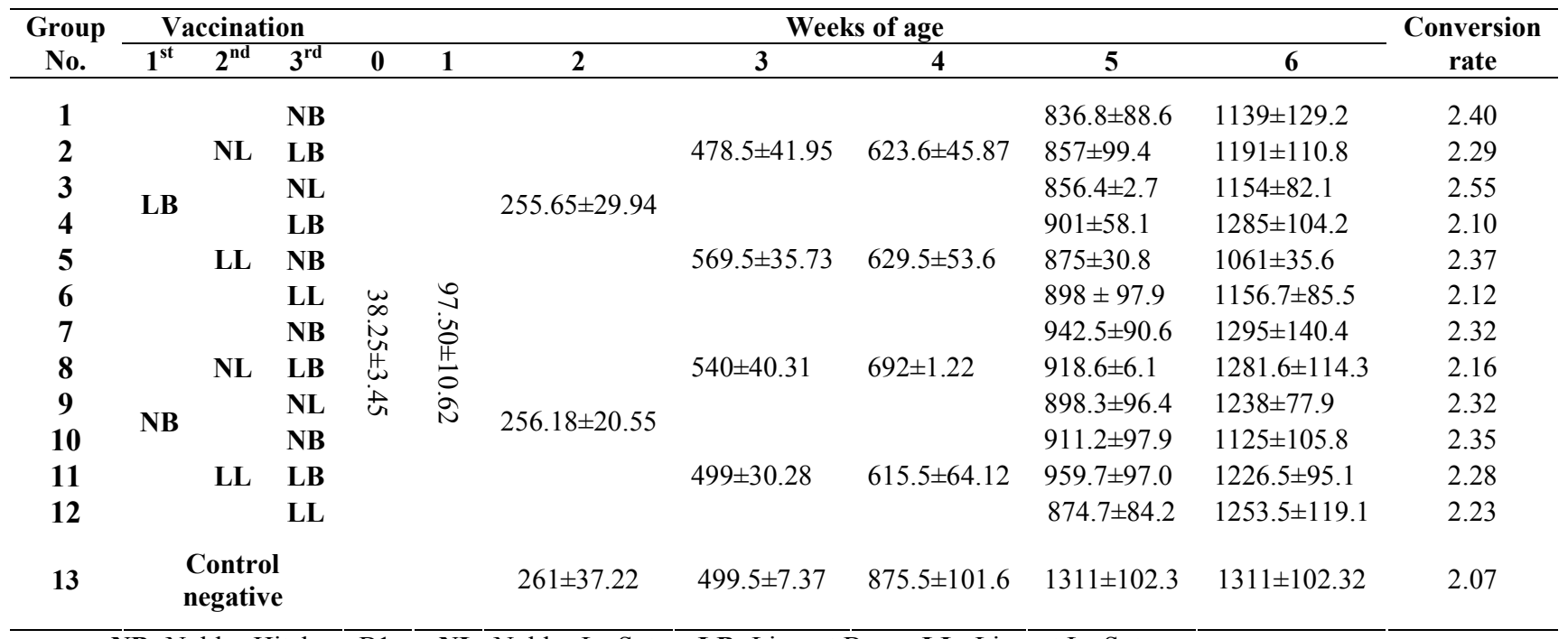

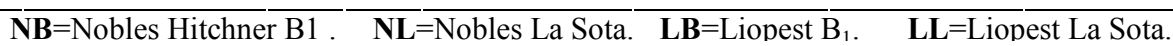

Table (5): Results of statistical analysis of body weight difference between groups at 40-days of age as seen in table (4).

\begin{tabular}{cccccccccccccc}
\hline Group No. & $\mathbf{1}$ & $\mathbf{2}$ & $\mathbf{3}$ & $\mathbf{4}$ & $\mathbf{5}$ & $\mathbf{6}$ & $\mathbf{7}$ & $\mathbf{8}$ & $\mathbf{9}$ & $\mathbf{1 0}$ & $\mathbf{1 1}$ & $\mathbf{1 2}$ & $\mathbf{1 3}$ \\
\hline $\mathbf{1}$ & & & & $* * *$ & & & $* * *$ & $* * *$ & & & & $*$ & $* * *$ \\
$\mathbf{2}$ & & & & & $* *$ & & & & & & & & $*$ \\
$\mathbf{3}$ & & & & $* *$ & & & $* *$ & $* * *$ & & & & & $* * *$ \\
$\mathbf{4}$ & & & & & $* * *$ & $* *$ & & & & $* *$ & & & \\
$\mathbf{5}$ & & & & & & & $* * *$ & $* * *$ & $* * *$ & & $* * *$ & $* * *$ & $* * *$ \\
$\mathbf{6}$ & & & & & & & & $* *$ & & & & & $* * *$ \\
7 & & & & & & & & & $* * *$ & & & \\
$\mathbf{8}$ & & & & & & & & & $* * *$ & & & \\
9 & & & & & & & & & $*$ & & $* *$ & $* * *$ \\
10 & & & & & & & & & & & &
\end{tabular}

$*=$ Significant difference between vaccinated groups at $*=p<0.05 * *=p<0.01 * * *=p<0.001$

Table (6): Results of challenge test in ND vaccinated chickens $(n=20)$.

\begin{tabular}{|c|c|c|c|c|c|}
\hline \multirow{2}{*}{ Group No. } & \multicolumn{3}{|c|}{ Vaccination } & \multicolumn{2}{|c|}{ Challenge test } \\
\hline & $1^{\text {st }}$ & $2^{\text {nd }}$ & $3^{\text {rd }}$ & No. of survivals & Protection rate \% \\
\hline 1 & \multirow{7}{*}{ LB } & \multirow{4}{*}{ NL } & NB & 17 & $85^{*}$ \\
\hline 2 & & & LB & 19 & 95 \\
\hline 3 & & & NL & 18 & 90 \\
\hline 4 & & & LB & 20 & $100 *$ \\
\hline 5 & & \multirow[t]{3}{*}{$\mathbf{L L}$} & NB & 19 & 95 \\
\hline 6 & & & LL & 20 & $100^{*}$ \\
\hline 7 & & & NB & 17 & $85^{*}$ \\
\hline 8 & \multirow{4}{*}{ NB } & \multirow[t]{2}{*}{ NL } & LB & 20 & $100^{*}$ \\
\hline 9 & & & NL & 20 & $100^{*}$ \\
\hline 10 & & \multirow{3}{*}{$\mathbf{L L}$} & NB & 19 & 95 \\
\hline 11 & & & LB & 20 & $100^{*}$ \\
\hline 12 & & & $\mathbf{L L}$ & 20 & $100^{*}$ \\
\hline 13 & \multicolumn{3}{|c|}{ Control negative } & 0 & 0 \\
\hline
\end{tabular}

$\mathbf{N B}=$ Nobles Hitchner $\mathrm{B}_{1} . \quad \mathbf{N L}=$ Nobles La Sota. $\quad \mathbf{L B}=$ Liopest $\mathrm{B}_{1} . \quad \mathbf{L L}=$ Liopest La Sota.

$*=$ Significant difference between vaccinated groups at $\mathrm{p}<0.05$. 
Table (7): Mean lesion score of CRD in ND vaccinated chickens ( $n=10)$.

\begin{tabular}{ccccc}
\hline \multirow{2}{*}{ Group No. } & \multicolumn{1}{c}{ Vaccination } & \multicolumn{2}{c}{ Lesion score } \\
\cline { 2 - 5 } & $\mathbf{1}^{\text {st }}$ & $\mathbf{2}^{\text {nd }}$ & $\mathbf{3}^{\text {rd }}$ & Mean \\
\hline $\mathbf{1}$ & & & $\mathbf{N B}$ & 1.6 \\
$\mathbf{2}$ & & $\mathbf{N L}$ & $\mathbf{L B}$ & 1.4 \\
$\mathbf{3}$ & $\mathbf{L B}$ & & $\mathbf{N L}$ & 1.1 \\
$\mathbf{4}$ & & & $\mathbf{L B}$ & 0.9 \\
$\mathbf{5}$ & & $\mathbf{L}$ & $\mathbf{N B}$ & 0.9 \\
$\mathbf{6}$ & & $\mathbf{L L}$ & 1.3 \\
$\mathbf{7}$ & & $\mathbf{N B}$ & 1.2 \\
$\mathbf{8}$ & & $\mathbf{N L}$ & $\mathbf{L B}$ & 1.2 \\
$\mathbf{9}$ & $\mathbf{N B}$ & & $\mathbf{N L}$ & 1.9 \\
$\mathbf{1 0}$ & & $\mathbf{N L}$ & $\mathbf{N B}$ & 0.9 \\
$\mathbf{1 1}$ & & & $\mathbf{L B}$ & 0.9 \\
$\mathbf{1 2}$ & & & $\mathbf{L L}$ & 1.5 \\
& & & & 0.6 \\
\hline
\end{tabular}
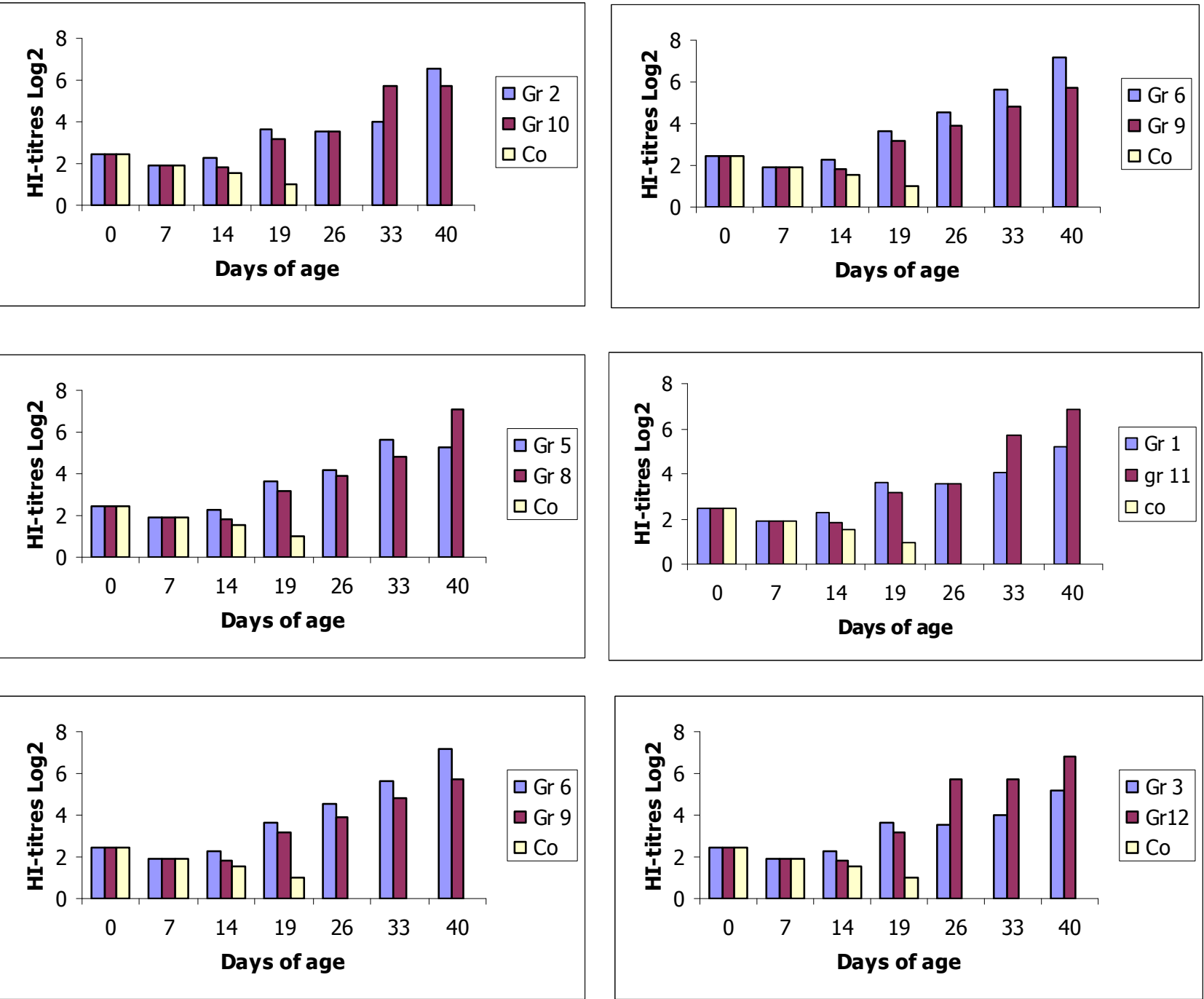

Fig. (1): Level of HI antibody $\log _{2}$ titers in sera of chickens vaccinated against ND.

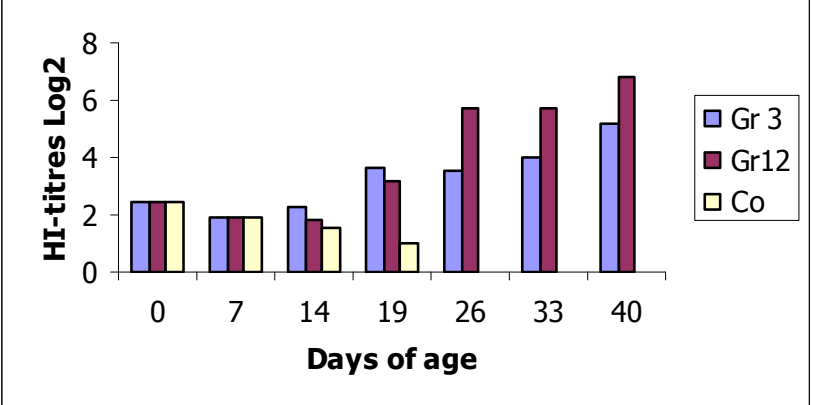




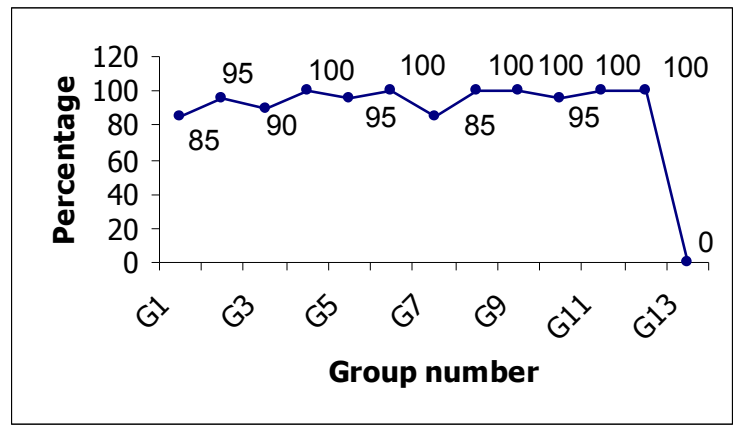

Fig. (2): Protection rate of challenged ND vaccinated chickens.

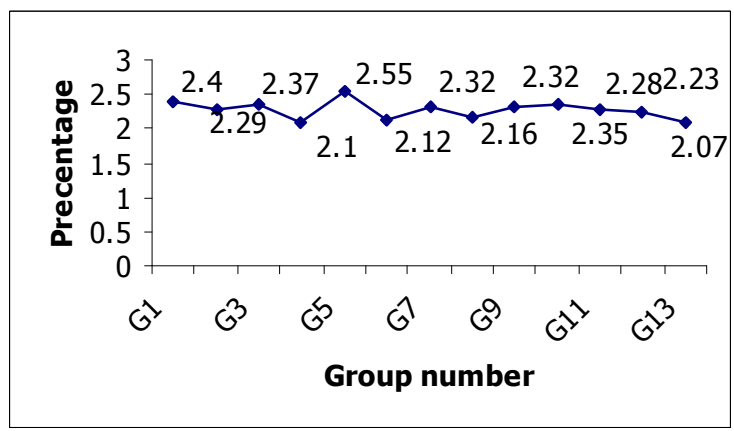

Fig. (3): Conversion rate of 40-days old ND vaccinated

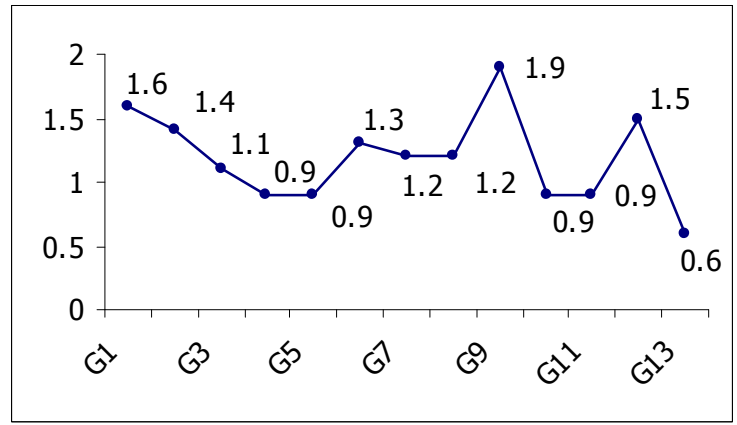

Fig. (4) : CRD lesion score in 40-days old ND vaccinated chickens.

received LB and LL vaccines. Results of challenge test (Table 6, Fig. 2) revealed statistically that the protection rate was only $85 \%$ for each of groups 1 and 7 which were significantly lower than groups 4, 6, 8, 9, 11 and $12(100 \%)$. Birds received all ND vaccines from the same source (group 6,9 and 12) showed $100 \%$ protection. In the other side, administration of LB vaccine instead of homologous La Sota at 33-days of age (groups 4 and 8 ) resulted in $100 \%$ protection rate as compared with $90 \%$ following heterologous $\mathrm{La}$ Sota (group 3). While groups 1, 7 and 10, which received, NB vaccine showed protection rates only $85 \%, 85 \%$ and $95 \%$, respectively.

Post-mortem lesions of dead challenged birds were typical lesions of VVNDV infection, while the intestinal lesions were more obvious in vaccinated group 1 and 7 than those of 3 and 5 . Results of the mean lesion score for CRD in vaccinated groups with different regimes (Table 7, Fig. 4) showed that vaccination with ND vaccinal strains source (1) inducing higher scores than vaccination with vaccines from source (2). Administration of LB vaccine at 33-days of age induced lower scores.

Vaccination of chicken groups with LB vaccine by ocular route at 33-days of age (boostered to 2 vaccinations) resulted in better immunity, better protection rates as well as higher performance than those received NB vaccine. Birds received LL vaccine 19-days of age following homologous vaccine revealed higher immunity and performance than those received NL vaccine.

\section{Discussion}

Newcastle disease live vaccines from lentogenic strains have been adopted to be used in the disease prevention since their first use until now. In our field there are vaccines from different sources, such vaccines are differ in their potency for prevention of the disease. In this study, we used ND vaccines from two sources for vaccination of broiler chicks serologically positive to Mycoplasmas.

The obtained mean $\mathrm{HI}$ titers at 40-days of age in group 6 and 8 that received vaccines from one source were $(7.21 \pm 1.78)$ and $(7.31 \pm 2.25)$, respectively. They were significantly higher than those of groups 1 (5.20 \pm 1.66$)$, group $3(5.20 \pm$ $1.20)$ and group $5(5.25 \pm 0.89)$ that received vaccines from different sources. Titers in groups 6 and 8 were also significantly higher than that of group $2(5.57 \pm 1.20)$ at $\mathrm{P}<0.05$. This result indicated that the usage of ND live vaccines from one source is better. Titers of group 8 (7.31 $\pm 2.25)$ was significantly higher than those of groups $9(5.77 \pm 1.87)$ and $10(5.73 \pm 1.61)$ at $\mathrm{P}<$ 0.05 .

General speaking, chicken groups received vaccine from the $2^{\text {nd }}$ source showed higher titers than those received vaccines from the $1^{\text {st }}$ source (groups 6 and 9). In addition, birds that were given Hitchner B1 and /or La Sota vaccines of source (2) at any time of vaccination age showed relatively higher titers. Similar results had been reported (Amer et al., 1993; Min et al., 2002).

Results of the mean body weight at the $6^{\text {th }}$ week of age pointed out that birds of nonvaccinated control group showed significantly $(\mathrm{P}<0.001)$ higher mean body weight $(1311 \pm$ 102.32) than those of vaccinated groups $1,3,6$ and 10 . The mean body weight in-group 10 was 
significantly lower than those of group 7 (1295 \pm 140.4), group $8(1281 \pm 114.3)$ at $\mathrm{P}<0.001$ and lower than that of group $9(1238 \pm 77.9)$ at $\mathrm{P}<0.05$. In addition, the obtained body weight values in groups 4,7 and 8 were significantly higher than those of groups $1(\mathrm{P}<0.001)$ and 3 $(\mathrm{P}<0.01)$. Bunens et al., (1983) found no significant difference in weight gain and feed conversion among groups received different vaccines.

In general, the usage of vaccines from homologous source induced improving in body weights than the usage of vaccines from the heterologous sources.

In addition, control non-vaccinated group showed higher feed conversion rate than all vaccinated chicken groups. Groups given $\mathrm{La}$ Sota ND strain vaccine at 33-days of age mostly showed lower rates than those received Hitchner.

Results of the challenge test indicated that birds of groups 1 and 7 that were given $2^{\text {nd }}$ and $3^{\text {rd }}$ vaccination from source (1) showed significantly lower protection rates $(85 \%)$ for each than those of groups $4,6,8,9,11$ and 12 that were given vaccines from source (2). In this way, Bananvare et al., (2001) concluded that, some vaccines were less potent than others up on comparing four commercial La Sota vaccines from different manufactures.

In the other side administration of Hitchner $B_{1}$ vaccine of source (2) instead of homologous La Sota at 33-days of age (groups 4 and 8) induced $100 \%$ protection percentage as compared with $90 \%$ following heterologus $\mathrm{La}$ Sota (group 3). Those results could be explained by findings of Thornton et al., (1980) who detected variation in protection among vaccinated chickens with vaccines made from the same strains, depending on their source. Also, Borland and Allan, (1980) found differences in the immunization capacities, potency levels and respiratory distress of $18 \mathrm{ND}$ vaccines from different sources. La Sota vaccines were more varied, more heterogenous and more immunogenic than $\mathrm{HB}_{1}$ vaccines. The relation between $\mathrm{HI}$ titers and challenge test had been discussed (Min et al., 2002).

CRD mean lesion scores in groups vaccinated with source (1) vaccines were higher than birds received vaccines from the other source. Administration of LB vaccine at 33-days of age shower lower scores than La Sota. Results that pointed out the role of vaccine in stimulation of CRD were reported (MacOwan et al., 1982; Gross, 1990; Nakamura et al., 1994).
Results of this work could be referred to the difference in the potency and in the immunogenicity or the antigenic relation between the vaccinal and the challenge strain. Similar explanation was stated (Schloer et al., 1975; Eidson and Kleven, 1980; Russel and Alexander, 1983).

We can conclude that when ND vaccines are used as preventive measure, they must be carefully chosen according to the disease history of the birds. Not all vaccines in the field are equal in their potency. Hitcher $B_{1}$ vaccines can be used as a $3^{\text {rd }}$ vaccination dose at 33-days of age in birds under Mycoplasma stress.

\section{References}

Allan, W. H.; Lancaster, J. E. and Toth, B. (1975): Newcastle disease vaccines, production and use. FAO, Rome, Itally.

Amer, M . M.; Khilfa, D. G.; Metwalli, A. S. E. and ElKady, M. F. (1993): Immune responce against Hichner $B_{1}$ vaccine in chickens infected with Mycoplasma. Beni-Suef, Vet. Med. Res., III(1): 108-123.

Anon (1971): Methods for examining poultry biologics and for identifying and quantifying avian pathogens. National Academy of science-Washington, D. C.

Awaad, M. H. H; Sahar, A. Zoulfakar; El-Shazely, M. O.; Manal, A. Afify and Osman, L. H. (2003): Effect of "Pediococcus acidilactic" on zootechnical Performance and E. coli infection in broiler chickens. Vet. Med. J. Giza., 51 (2): 273- 281.

Bananvare, P. S.; Kulkarni, D.D. and Gujar, M. B. (2001): Quality assessment of La Sota strain vaccines. Ind. J. of Comp. Microbiol. Immunol. Inf. Dis., 22 (2): 154-155. Borland, L. J. and Allan, W. H. (1980): Laboratory tests for comparing live lentognic Newcastle disease vaccines. Avian Pathol., 9 (1): 45-59.

Bunens, B.; Spanoghe, L.; Devos, A. and Vlaene, N. (1983): Commercial Newcastle disease vaccines: II: Vaccination of SPF layer chicks and ordinary broilers with five vaccines derived from La Sota and clone 30 virus strains. Valaams Diergeneeskundig Tijdschrift., 52 (4): 237 254.

Chabra, P. C. and Goel. M. C. (1981): Immunological response of chickens to Mycoplasma gallisepticum infection. Avian Dis., 25: 279-93.

Gaunson, J. E.; Philip, C. J. ; Whithear, K. G. and Browning, G. F. (2000): Lymphocytic infiltration in the chicken trachea in response to Mycoplasma gallisepticum infection. Microbiology Reading, 146: 1223-1229.

Goldhaft, T. M. (1980): Historical note on the origin of the La Sota strain of Newcastle disease virus. Avian. Dis., 24: 297-301.

Gross, W. B. (1990): Factors affecting the development of respiratory disease complex in chickens. Avian Dis., 34: 607-610.

Eidson, C. S. and Kleven, S. H. (1980) : Vaccination of chickens with a clone-selected La Sota strain of Newcastle disease virus. Poult. Sci., 59 (5): 979-984.

Hitchner, S. B. and Johnson. E. P. (1948): A virus of low virulence for immunizing fowls against Newcastle disease (avian pneumoencephalitis). Vet Med., 43:525-530.

Kaleta, E. F. and Sigmonn, O. (1971): Comparative studies on the demonstration of hemagglutinating inhibiting 
and neutralizing antibodies after vaccination against Newcastle disease. Arch. Geflugelk., 35: 79.

Lancaster, J. and Alexander, D. J. (1975) : A Newcastle disease virus and spread. A review of some of the literature. Canada Depart. Of Agri., Monograph No. 11.

MacOwan, K. J.; Randall, C. J.; Jones, H. G. R. and Brand. T. F. (1982): Association of Mycoplasma synoviae with respiratory disease of broilers. Av. Pathol., 11: 235244.

Min, W. Q.; P. J. Wu, W. K. Dong and Z. T. Chui (2002): Immunocpotency test on some attenuated vaccines against Newcastle disease chicken. Chinese. J. Vet. Med., 28 (5): 12-13.

Nakamura, K.; Ueda, H.; Tanimura, T. and Noguchi, K. (1994): Effect of mixed live vaccine (Newcastle disease and infectious bronchitis) and Mycoplasma gallisepticum on the chicken respiratory tract and on Escherichia coli infection. J. comp Pathol., 111: 33-42.

OIE (2004): Manual of diagnostic tests and vaccines for terrestrial animals. $5^{\text {th }}$ ed. Office International des Epizootics, Paris, France.

Panshsin, A.; Shihmanter, E.; Weisman, Y.; Orveli, C. and Lipkind, M. (2002): Antigenic heterogenicity amongst the field isolated Newcastle disease virus (NDV) in relation to vaccine strain Part NII: Studies on viruses isolated from domestic birds in Israel. Comp. immunol. Microbiol. Inf.
Dis., 25 (3): 173-185.

Reddy, S. K.; Pratik, S.; Amer, S.; Newman, J. A.;

Singh, P. and Silim. A. (1998): Lympho proliferative responses of specific pathogen-free chickens to Mycoplasma gallisepticum strain PG31. Avian Pathol., 27: 277-283.

Reed, L. J. and Muench, H. (1938): A simple method of estimating fifty percent end point. Am. J. Hyg., 27: 493497.

Russell, P. H. and Alexander, D. J. (1983): Antigenic variation of Newcastle disease virus strains detected by monoclonal antibodies. Arch. of Virol., 75 (94): 243-253.

Saif, Y. M.; Barnes, H. J.; Fadly, A. M.; Glisson, J. R.; McDougald, L. R. and Swayne, D. E. ( 2003): Diseases of Poultry, 11th Ed., Iowa State Press, A Blackwell Publishing Co.

Schloer, G.; Spaltin, J. and Hanson, R. P. (1975): Newcastle disease virus antigens and strain variation. Am. J. Vet. Res., 36 (4): 505-508.

Sheble, A. and Reda, I. M. (1976): Cited by Khaphagy, A. K. (1977): Thesis M. V. Sc., Fac. Vet. Med., Cairo Univ. Takatsy, G. Y. (1956): The use of spiral loops in serological methods. Acta. Microbiol. Hung.,3: 191.

Thornton, D. H.; Hopkina , I. G. and Hebert, C. N. (1980): Potency of live Newcastle disease vaccines. Avian Pathol., 9 (3): 457-464.

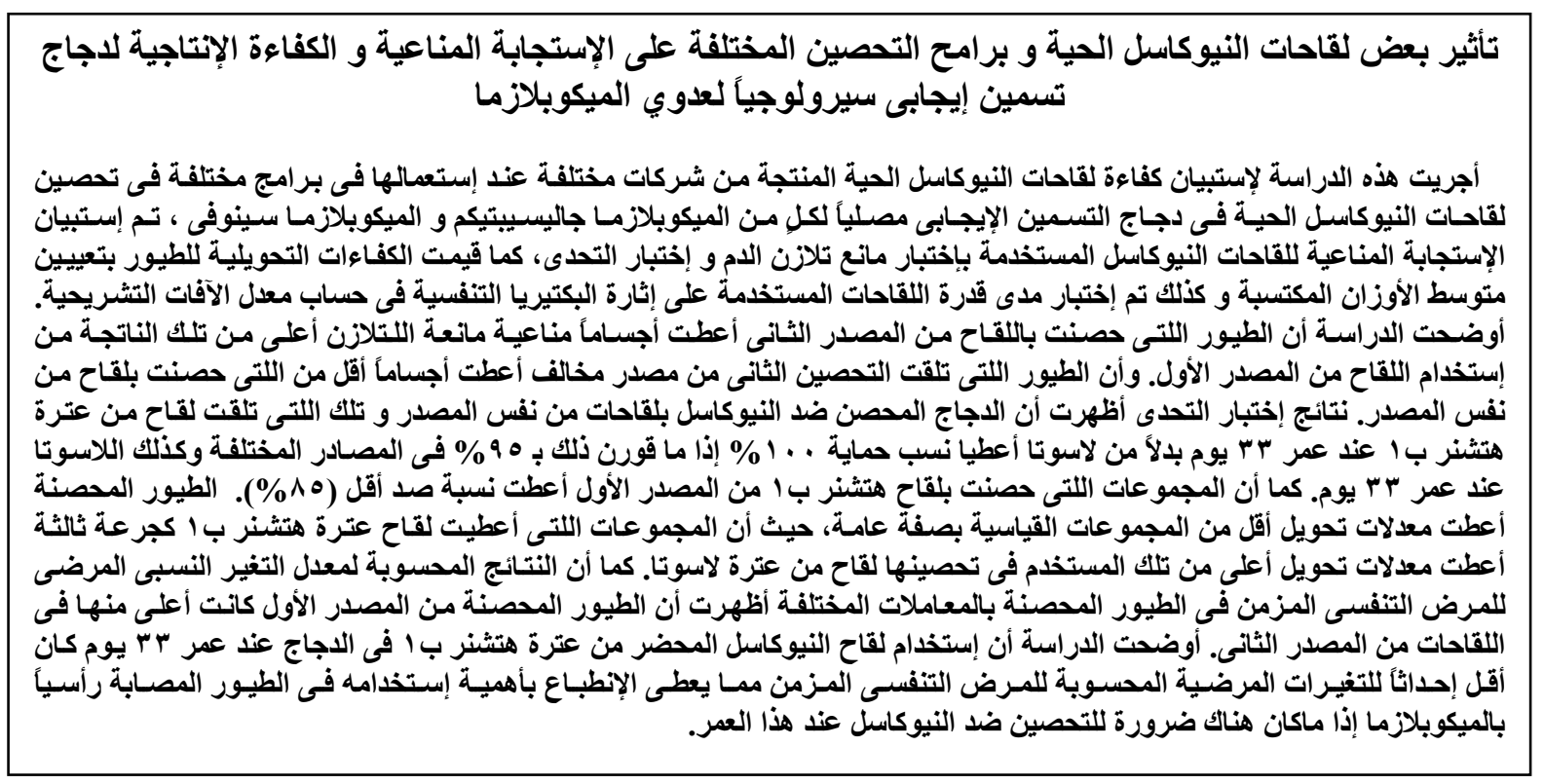

